\title{
Spor Bilimleri Fakültesi Öğrencilerinin Akademik Erteleme Düzeylerinin İncelenmesi
}

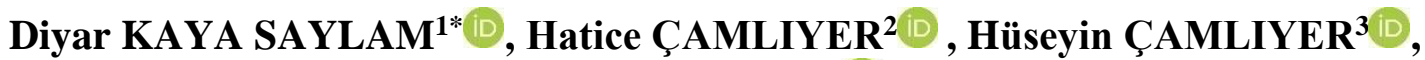 \\ Nazlıcan EKİM 4 \\ ${ }^{1}$ Manisa Celal Bayar Üniversitesi, Spor Bilimleri Fakültesi.
}

Orijinal Makale

Gönderi Tarihi: 14.11.2021
Kabul Tarihi: 25.12.2021

DOI:10.30769/usbd.1023013

Online Yayın Tarihi: 31.12 .2021

\section{$\ddot{O} z$}

Bu araştırmanın amacı Spor Bilimleri Fakültesi (SBF) öğrencilerinin akademik erteleme (AE) düzeylerini çeşitli değişkenler açısından ortaya koymaktır. Tarama modelindeki araştırmanın çalışma grubu, kolayda örnekleme tekniği ile belirlenmiştir. Araştırmanın örneklemini Manisa Celal Bayar Üniversitesi Spor Bilimleri Fakültesinde öğrenim gören 271'i kadın 485'i erkek toplamda 756 öğrenci oluşturmaktadır. Veri toplama aracı olarak Çakıcı (2003) tarafından geliştirilen "Akademik Erteleme Ölçeği”" (AEÖ) ve "Kişisel Bilgi Formu" kullanılmıştır. AEÖ’nin bu çalışma için Cronbach alpha değeri ,768 bulunmuştur. Verilerin çözümlenmesinde aritmetik ortalama, standart sapma ile gruplar arasındaki farklar için t-testi ve tek yönlü ANOVA testleri kullanılmıştır. Araştırma bulguları öğrencilerin AEÖ’den aldıkları ortalama puanların orta düzeyde olduğunu belirlemiştir. Cinsiyet değişkeni açısından istatistiksel olarak anlamlı farklılık elde edilmiştir. Kadınların erkeklere göre akademik ertelemeleri daha düşük olduğu tespit edilmiştir. Sınıf değişkenine göre $\left(F_{(3-752)}=3,263, p=, 021\right)$ anlamlı bir farkl11ık bulunmaktadır bu farklılık 1. ve 4. Sınıflar arasındadır. Sınıf düzeyi arttıkça AE puan ortalamalarının da arttığı görülmektedir. Akademik başarıları incelendiğinde $\left(\mathrm{F}_{(4-751)}=17,795, \mathrm{p}=, 00\right)$ anlamlı farklılık gösterirken, bölümler arasında anlamlı bir farklılık elde edilmemiştir. SBF öğrencilerinin AE puan ortalamalarının orta düzeyde olduğu söylenebilir. Erkeklerin kadınlara göre AE'nin yüksek olma sebebi daha az sorumluluk sahibi olma, akademik çalışmaları kadınca görmeleri ve risk alma duygularından kaynaklanıyor olabilir. Son sınıf ve birinci sınıf arasındaki farklılı̆̆ın sebebi son sınıfların daha az okulda bulunmaları (staj, proje vb), birinci sınıfların üniversite sınavını kazanabilmek için sahip oldukları ders çalışma alışkanlıklarını sürdürmeleri olabilir. Erkek öğrencilerin kız öğrencilere, son sınıfların birinci sınıflara göre AE düzeyleri daha yüksektir. Bölümler arasında AE düzeyleri açısından bir farklılık sergilemediği sonucuna ulaşılmıştır.

Anahtar kelimeler: Akademik erteleme, spor bilimleri fakültesi, erteleme.

\section{Investigation of Academic Procrastination Levels of Faculty of Sports Sciences Students}

\begin{abstract}
The aim of this research is to reveal the academic procrastination (AP) levels of the Faculty of Sport Sciences (FSS) students in terms of various variables. The study group of the research in the screening model was determined by convenience sampling technique. The sample of the study consists of 271 female and 485 male students in total, 756 students studying at MCBU Faculty of Sport Sciences. "Academic Procrastination Scale" (APS) developed by Çakıcı (2003) and "Personal Information Form" were used as data collection tools. The Cronbach alpha value of this study was found to be ,768. In the analysis of the data, arithmetic mean, standard deviation and t-test for differences between groups and one-way ANOVA tests were used. The research findings determined that the average scores of the students in APS were at a moderate level. Statistically in terms of gender variable, a statistically significant difference was obtained in terms of gender variable. It has been determined that women have lower AP than men. According to the class variable $\left(\mathrm{F}_{(3-752)}=3,263, \mathrm{p}=, 021\right)$, there is a significant difference between the 1st and 4th Grades. It is seen that as the grade level increases, the AP score averages also increase. When their academic achievements were examined $\left(\mathrm{F}_{(4-751)}=17,795, \mathrm{p}=, 00\right)$, there was no significant difference between departments. It can be said that the AP point averages of FSS students are at a medium level. The difference between seniors and first graders may be due to the fact that seniors attend less schools (internships, projects, etc.) and freshmen maintain their study habits in order to pass the university entrance exam. AP levels of male students are higher than female students, and senior students' AP levels are higher than first-year students. There is no difference between departments.
\end{abstract}

Keywords: Academic procrastination, faculty of sports sciences, procrastination. 


\section{GíRiş}

Üniversite yaşamında bireysel tercihlerin önem taşıdığı, kendi kendine öğrenme ve araştırma yapma gibi öğrencilerin alması gereken birçok akademik görev ve sorumluluk bulunmaktadır (Uzun-Özer, 2005). Ancak bazı bireyler görevleri erteleyerek akademik erteleme davranışı sergileyebilmektedirler (Özer ve Altun, 2011). Akademik erteleme davranışı, öğrencilerin sınav ve sınavlara hazırlık yapmak, dönem ödevi hazırlamak, okula ait yapılması gereken idari işleri yapmak, yapması veya katılması gereken görevleri yerine getirmek gibi temel akademik işlevlerini ertelemesi ve bu ertelemeden dolayı kaygı hissetmeleri olarak ifade edilmektedir (Solomon ve Rothblum, 1984). Diğer bir değişle akademik erteleme davranışı "akademik görevlere başlamayı ya da tamamlamayı rasyonel olmayan gerekçelerle ileri bir zamana bırakma eğilimi”" şeklinde aktarılmaktadır (Senecal, Julien ve Guay, 2003). Akademik erteleme davranışı sergileyen öğrenci sayısının çokluğu araştırmacıları akademik ertelemeyi anlamaya ilişkin araştırmalar yapmaya yöneltmiş̧tir (Özer ve Altun, 2011). Akademik erteleme davranışının sebebine yönelik akademik veya bireysel özelliklerden kaynaklandığını belirten bir çok araştırma mevcuttur (Albayrak, 2014; Bojuwoye, 2019; Karataş ve Bademcioğlu, 2015; Kutlu-Abu ve Saral, 2016; Kutlu-Demir, 2016; Nayak, 2019; Vural ve Gündüz, 2019). Bazı araştırmalarda ise öğrenme görevinin kişiye ilgi çekici gelmesi ve sevmesi ile akademik erteleme davranışı arasında negatif yönde bir ilişki olduğunu göstermektedir (Vural ve Gündüz, 2019).

Son yıllarda Beden Eğitimi ve Spor alanında yapılan bazı çalışmalarda; bu alanda öğrenim gören erkek öğrencilerin kadın öğrencilere göre akademik ve genel erteleme davranışını daha yoğun olarak gösterdikleri, genel erteleme davranışına daha az sahip olduklarında ve özyeterlik inancına (düşük oranlarda da olsa) sahip olduklarında BESYO öğrencilerinden daha az akademik erteleme davranışı gösterebileceklerini öngörmektedir (Şirin ve Duman, 2018). Öz düzenleme becerisine ait olan sınav kaygısı ve öz yeterlik alt boyutlarının ve öz yeterliğe ait olan yılmama alt boyutlarının akademik erteleme eğiliminin önemli bir yordayıcısı olduğu görülmüştür (Filiz ve Doğar, 2021). Sarıkabak, Eyuboğlu ve Ayrancı'nın 2018 yılında Bocce sporcularında yapmış olduğu araştırmada ise duygusal zekâ alt boyutlarının (iyimserlik, duyguların kullanımı ve duyguların değerlendirilmesi) akademik erteleme davranışı üzerinde anlamlı etki oluşturduğu görülmüş̧ür.

Akademik erteleme davranışı sergileyen öğrencilerin daha fazla stres ve sağlık sorunu yaşadıkları (Tice ve Baumeister, 1997), dönem derslerinde başarısızlık oldukları, öğrenim sürelerini uzatıp hatta üniversiteden ayrılmak gibi olumsuz sonuçlarla karşılaş̧ıkları ifade edilmektedir (Akbay ve Gizir, 2010; Guzey, 2007; Lay,1986). Bu çalışmada, Spor Bilimleri Fakültesinde öğrenim gören öğrencilerin akademik erteleme davranış düzeylerinin belirlenmesi amaçlanmıştır. Bu çalışma, beden eğitimi ve spor literatüründe bir farkındalık oluşturacak olup, araştırmanın bundan sonra planlanan araştırmalarda, akademik erteleme davranışının sebeplerine, azaltılması ya da düzeltilmesine yönelik konulara katkısı olacağı düşünülmektedir. 


\section{YÖNTEM}

\section{Araştırma Modeli}

Araştırmada nicel araştırma yöntemlerinden tarama modeli (betimsel yöntem) kullanılmıştır. $\mathrm{Bu}$ modelde araştırmaya konu olan olay, birey ya da nesne, kendi koşulları içinde ve olduğu gibi tanımlanmaya çalışılır (Karasar, 2012).

\section{Çalışma Grubu}

Araştırma 2017-2018 eğitim-öğretim yılı Manisa Celal Bayar Üniversitesi Spor Bilimleri Fakültesinde öğrenim gören öğrenciler üzerinde yapılmıştır. Araştırmada olasılığa dayalı olmayan yöntemlerden kolayda örnekleme kullanılmıştır (Altunışık, Coşkun, Bayraktaroğlu ve Y1ldırım, 2017). Araştırmayı 271'i kadın $\left(\bar{x}_{\text {yaş }}=21,22\right) 485$ 'i erkeklerden $\left(\bar{x}_{\text {yaş }}=21,92\right)$ oluşan toplam 756 öğrenci katılmıştır.

\section{Veri Toplama Aracı}

Araştırmada veri toplama aracı olarak Spor Bilimleri Fakültesi öğrencilerinin demografik özelliklerine ilişkin bilgileri saptamak için araştırmacılar tarafından hazırlanan kişisel bilgi formu ile Çakıcı (2003) tarafından geliştirilen “Akademik Erteleme Ölçeği” kullanılmıştır.

Kişisel Bilgi Formu: Bu bölümde çalışmaya katılan bireylerin yaşları, cinsiyetleri, bölümleri, sınıfları ve Genel Ağırlıklı Not Ortalamaları (GANO) belirlenmiştir.

Akademik Erteleme Ölçeği: Çakıcı (2003) tarafından geliştirilen “Akademik Erteleme Ölçeği” beşli Likert tipi ölçek, 19 maddeden ve oluşmaktadır. Ölçeğin bu çalışma için Cronbach alpha değeri 768 bulunmuştur. Akademik Erteleme Ölçeği maddelerinin 12'si olumsuz, 7'si (1, 4, 7, $9,11,13,17)$ olumludur. Bu ifadeler "beni hiç yansıtmıyor", "beni çok az yansitıyor", "beni biraz yansitıyor", "beni çoğunlukla yansitıyor","beni tamamen yansitıyor" biçimindedir. Ölçekte akademik erteleme davranışı içeren bir ifadeye "beni hiç yansıtmıyor" diyenler 1, "beni tamamen yansitıyor" diyenler 5 puan alacak biçimde tek yönlü puanlanmaktadır.

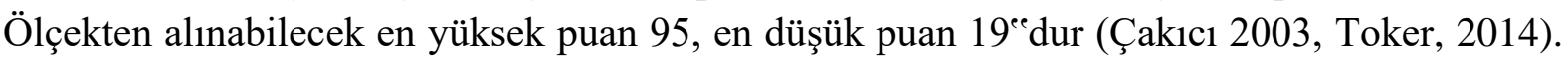
Gönüllü katılımcılara veri toplama araçları hakkında sözlü bilgi verildikten sonra anket yöntemiyle araştırmanın verileri toplanmıştır.

\section{Verilerin Analizi}

Verilerin çözümlenmesinde frekans, aritmetik ortalama, standart sapma ile gruplar arasındaki farklar için t-testi ve tek yönlü ANOVA testleri kullanılmıştır.

\section{BULGULAR}

Araştırmanın bu bölümünde istatistiksel analizler neticesinde elde edilen verilere ilişkin bulgu ve yorumlara yer verilmiştir.

Tablo 1. Spor bilimleri fakültesi öğrencilerinin demografik bilgilerine göre dağılımları

\begin{tabular}{cccccc}
\hline Bölüm & Sayı (N) & \% & Sınıf & Sayı (N) & \% \\
\hline BEÖ & 144 & 19,0 & 1. Sınıf & 248 & 32,8 \\
AEB & 146 & 19,3 & 2. Sınıf & 128 & 16,9 \\
SYB & 280 & 37,0 & 3. Sınıf & 206 & 27,2 \\
REK & 186 & 24,6 & 4. Sınıf & 186 & 23,0 \\
Toplam & 756 & 100,0 & Toplam & 756 & 100,0 \\
\hline GANO & Sayı (N) & \% & GANO & Sayı (N) & \% \\
\hline 0-1,80 Çok Zayıf & 85 & 11,2 & $\mathbf{3 , 0 1 - 3 , 5 0 ~ I ̇ y i ~}$ & 162 & 21,4 \\
$\mathbf{1 , 8 1 - 2 , 5 0 ~ Z a y ı f ~}$ & 184 & 24,3 & $\mathbf{3 , 5 1 - 4 , 0 0 ~ C ̧ o k ~ I ̇ y i ~}$ & 67 & 8,9 \\
$\mathbf{2 , 5 1 - 3 , 0 0 ~ O r t a ~}$ & 258 & 34,1 & Toplam & 756 & 100,0 \\
\hline
\end{tabular}


Tablo 1'e göre araştırmaya katılan Spor Bilimleri Fakültesi (SBF) öğrencilerinin \%37'si (n=280) Spor Yöneticiliği Bölümü (SYB), \%24,6's1 (n=186) Rekreasyon bölümü (REK), \%19,3’ü (n=146) Antrenörlük Eğitimi Bölümü (AEB), \%19’u (n=144) Beden Eğitimi Öğretmenliği (BEÖ) bölümlerinden oluşmaktadır. Öğrencilerin \%32,8’i $(n=248)$ 1.Sınıf, \%27,2'si (n=206) 3.Sinıf, \%23'ü (n=186) 4.Sınıf ve \%16,9'u (n=128) 2.Sınıfta öğrenim görmektedir. Öğrencilerin Genel Ağırlıklı Not Ortalamaları (GANO) incelendiğinde \%34,1'i $(n=258)$ orta, \%24,3'ü $(n=184)$ zayıf, \%21,4'ü $(n=162)$ iyi, \%11,2'si $(n=85)$ çok zayıf ve $\% 8,9$ 'u $(\mathrm{n}=67)$ ise çok iyi düzeydedir.

Tablo 2. Akademik erteleme ölçeğinden elde edilen puanlara ilişkin betimsel istatistikler

\begin{tabular}{lccccc}
\hline Akademik Erteleme Ölçeği (AEÖ) & N & Min. & Maks. & $\overline{\mathbf{x}}$ & Ss \\
\hline AEÖ Puanı & 756 & 24 & 95 & 57,78 & 10,02 \\
\hline
\end{tabular}

Tablo 2'e göre Akademik erteleme ölçeğinin toplam puan ortalaması ( $\overline{\mathrm{x}}=57,78)$ olduğu görülmektedir. Araştırma bulguları öğrencilerin ölçekten aldıkları ortalama puanların ölçek orta puanı kadar olduğunu belirlemişstir.

Tablo 3. Spor bilimleri fakültesi öğrencilerinin akademik erteleme puanlarının cinsiyet değişkenine göre $\mathrm{t}$ test sonuçları

\begin{tabular}{lccccccc}
\hline & Grup & N & $\overline{\mathbf{x}}$ & S & sd & T & p \\
\hline \multirow{2}{*}{ AEÖ Puanı } & Kadın & 271 & 56,36 & 9,81 & 754 & 2,94 &, $\mathbf{0 0 3}$ \\
& Erkek & 485 & 58,58 & 10,05 & & & \\
\hline
\end{tabular}

$\mathrm{p}<.05$

Tablo 3'e göre Spor Bilimleri Fakültesi öğrencilerinin akademik erteleme ölçek puanları cinsiyet açısından anlamlı bir farklılık göstermektedir $(\mathrm{p}<.05)$. Ortalamalar incelendiğinde kadınların $(\overline{\mathrm{x}}=56.36)$ akademik erteleme puanlarının erkeklerinkinden $(\overline{\mathrm{x}}=58.58)$ daha düşük olduğu görülmektedir.

Tablo 4. Spor bilimleri fakültesi öğrencilerinin akademik erteleme puanlarının öğrenim gördükleri bölüme göre anova sonuçları

\begin{tabular}{|c|c|c|c|c|c|c|}
\hline & & $\mathbf{N}$ & & $\overline{\mathbf{x}}$ & & \\
\hline \multirow{6}{*}{ AEÖ Puanı } & BEÖ & 144 & & 56,47 & \multicolumn{2}{|c|}{9,84} \\
\hline & AEB & 146 & & 58,83 & \multicolumn{2}{|c|}{11,04} \\
\hline & SYB & 280 & & 57,94 & \multicolumn{2}{|c|}{9,42} \\
\hline & REK & 186 & & 57,74 & \multirow{2}{*}{\multicolumn{2}{|c|}{$\begin{array}{l}10,14 \\
10,02\end{array}$}} \\
\hline & Total & 756 & & 57,78 & & \\
\hline & Varyansın Kaynağı & $\begin{array}{l}\text { Kareler } \\
\text { Toplamı }\end{array}$ & sd & $\begin{array}{c}\text { Kareler } \\
\text { Ortalaması }\end{array}$ & $\mathbf{F}$ & $\mathbf{p}$ \\
\hline \multirow{3}{*}{ AEÖ Puanı } & Gruplar Aras1 & 414,33 & 3 & \multirow{3}{*}{$\begin{array}{l}138,11 \\
100,26\end{array}$} & \multirow{3}{*}{1,37} & \multirow{3}{*}{,24 } \\
\hline & Grup içi & 75397,80 & 752 & & & \\
\hline & Toplam & 75812,13 & 755 & & & \\
\hline
\end{tabular}

$\mathrm{p}<05$

Spor bilimleri fakültesi öğrencilerinin akademi erteleme puanları öğrenim gördükleri bölüme göre anlamlı bir farklılık göstermemektedir ( $p>.05)$. Dördüncü sınıfın akademik erteleme puan ortalaması birinci sınıftan daha yüksektir. 
Kaya-Saylam, D., Çamlıyer, H., Çamlıyer, H. ve Ekim, N. (2021). Spor bilimleri fakültesi öğrencilerinin akademik erteleme düzeylerinin incelenmesi. Ulusal Spor Bilimleri Dergisi, 5(2), 146-153.

Tablo 5. Katılımcıların sınıf değișkeni bazlı aritmetik ortalama tanımlayıcı istatistikleri

\begin{tabular}{ccccc}
\hline & & $\mathbf{N}$ & $\overline{\mathbf{x}}$ & $\mathbf{s s}$ \\
\hline & 1, sinif & 248 & 56,08 & 9,91 \\
\multirow{4}{*}{ AEÖ Puan1 } & 2, sinif & 128 & 58,14 & 9,31 \\
& 3,sinif & 206 & 58,22 & 10,93 \\
& 4, sinif & 174 & 59,44 & 9,23 \\
& Toplam & 756 & 57,78 & 10,02 \\
\hline
\end{tabular}

Tablo 5'te katılımcıların sınıflara göre Akademik erteleme aritmetik ortalama ve standart sapma değerleri verilmiştir.

Tablo 6. Katılımcıların akademik erteleme ortalamalarının sınıf değişkenine göre ANOVA test sonuçları

\begin{tabular}{llcccccc}
\hline & $\begin{array}{l}\text { Varyansın } \\
\text { Kaynağı }\end{array}$ & $\begin{array}{c}\text { Kareler } \\
\text { Toplamı }\end{array}$ & sd & $\begin{array}{c}\text { Kareler } \\
\text { Ortalaması }\end{array}$ & F & p & $\begin{array}{c}\text { Anlamlı } \\
\text { Fark }\end{array}$ \\
\hline \multirow{4}{*}{ AEÖ Puanı } & Gruplar Arası & 1250,79 & 3 & 416,93 & & & \\
& Grup içi & 74561,34 & 752 & & 4,20 & $\mathbf{0 0 6}$ & 1 ,ve 4, sınıf \\
& Toplam & 75812,13 & 755 & 99,15 & & & \\
\hline
\end{tabular}

$\mathrm{p}<, 05$

Tablo 6'da SBF öğrencilerinin akademik erteleme düzeyleri öğrenim gördükleri sınıflara göre anlamlı bir fark olduğunu göstermektedir $\left(\mathrm{F}_{(3-752)}=4,20, \mathrm{p}<, 05\right)$. Anlamlı farklılığın 1, ve 4, Sınıflar arasında olduğu tespit edilmiştir.

\section{TARTIŞMA VE SONUÇ}

Araştırma bulguları öğrencilerin ölçekten aldıkları ortalama puanların ölçek orta puanı kadar olduğunu belirlemiştir. Bu durum cinsiyet faktörü açısından da kendini göstermiştir. Erkeklerin kadınlara göre AE'nin yüksek olma sebebi daha az sorumluluk sahibi olma, akademik çalışmaları kadınca görmeleri, kontrole karşı isyan ve risk alma duygularından kaynaklanıyor olabilir. Cinsiyet açısından araştırmamızı destekler nitelikte çalışmalar bulunmaktadır (Balkıs, 2006; Çakıc1, 2003; Çetin, 2016; Özer, Demir ve Ferrari, 2009).

Spor bilimleri fakültesi öğrencilerinin akademik erteleme puanları öğrenim gördükleri bölüme göre anlamlı bir farklılık göstermemektedir ( $>$,05). Farklı alanlardaki bölümlerle kıyaslandığında da benzer sonuçlar elde edilmiştir (Onağ, Onağ ve Yıldız, 2012). Literatür incelendiğinde lise düzeyinde incelendiğinde öğrenim gördükleri okul türüne göre akademik ertelemelerinde farkl1 bulgular ortaya koyan araştırmalar mevcuttur (Çetin, 2016; Ekinci, 2011; Gürültü ve Deniz, 2017; Yiğit ve Dilmaç, 2015). Üniversite düzeyinde ise farklı fakültelerde yapılmış çalışmalarda bölümler arasında anlamlı farklılık tespit edilmiştir (Çeri, Çavuşoğlu ve Gürol, 2015; Ekşi ve Dilmaç, 2010).

SBF öğrencilerinin akademik erteleme düzeyleri öğrenim gördükleri sınıflara göre istatistiksel olarak anlamlı bir fark olduğu $\left(\mathrm{F}_{(3-52)}=4,20, \mathrm{p}<, 05\right)$. Bu farklılı̆̆ın sebebini 1, ve 4, Sınıflardan kaynaklanmaktadır. Dördüncü sınıfin $(\overline{\mathrm{x}}=59,44)$ akademik erteleme puan ortalaması birinci sinıftan $(\overline{\mathrm{x}}=56,08)$ daha yüksektir. Bunun sebebi son sınıfların daha az okulda bulunmaları (staj, proje vb), birinci sınıfların üniversite sınavını kazanabilmek için sahip oldukları ders çalışma alışkanlıklarını sürdürmeleri olabilir. Alan yazın araştırmalarında ortaya çıkan bulgular 
araştırmamızı destekler yöndedir (Yaycı ve Düşmez, 2016). Araştırmacılar bu durumu yaş değişkeni ile de ilişkilendirmiş olup yaşı büyük olanların daha fazla erteleme davranışı içerisinde olduklarını belirtmişlerdir (Çakıcı, 2003; Uzun-Özer, 2009).

Ölçek genel ağırlıklı not ortalamalarına göre incelendiğinde istatistiksel olarak anlamlı bir fark

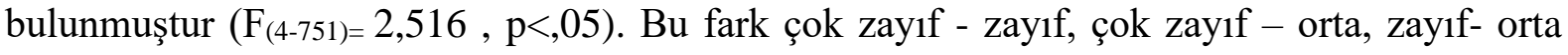
arasından kaynaklanmaktadır. Ortalamalar incelendiğinden GANO çok zayıf olan öğrencilerin $(\overline{\mathrm{x}}=54,84)$ akademik erteleme puanının zayıf $(\overline{\mathrm{x}}=58,56)$ ve orta $(\overline{\mathrm{x}}=58,46)$ olan öğrencilere göre daha düşük olduğu görülmektedir. Alan yazı incelendiğinde lise ve üniversite öğrencilerinde akademik erteleme ile akademik başarı arasında ağırlıklı olarak negatif yönde bulgulara rastlanmaktadır (Bulut ve Ocak, 2017; Çakıcı, 2003; Ekinci, 2011; Joubert, 2015; Kim ve Seo, 2015; Rosario, Schrimshaw, Hunter ve Levy-Warren, 2009). Araştırmamızda GANO'ları çok zayıf olan öğrencilerin akademik erteleme düzeylerinin diğerlerinden düşük olmasının sebebi akademik görev ve sorumluluğu üstlenmemelerinden, motivasyon eksikliğinden kaynaklanıyor olabilir.

Sonuç olarak bu araştırmada; erkek öğrencilerin kız öğrencilere göre son sınıfların birinci sınıflara göre AE düzeyleri daha yüksektir. GANO'sı çok zayıf olan öğrencilerin GANO'sı zayıf ve orta düzeyde olan öğrencilere göre AE düzeyleri daha düşüktür. Farklı bölümlerlerde öğrenim gören öğrenciler arasında AE düzeyleri açısından bir farklılık sergilemediği sonucuna ulaşılmıştır. Akademik erteleme davranışının nedenlerini ortaya koyan, farklı psikososyal değişkenlerle inceleyen araştırmalar yapılabilir. Davranışları azaltmak amacıyla öğrenciler rehberlik ve psikolojik danışma servislerine yönlendirilebilirler. Öğretim üyeleri; ödev, sunum, proje vb gibi akademik görevleri süreç içerisinde parametrelendirerek değerlendirebilir.

Yayın Etiği: Bu çalışmanın hazırlanma ve yazım sürecinde "Yükseköğretim Kurumları Bilimsel Araştırma ve Yayın Etiği Yönergesi” kapsamında bilimsel, etik ve alıntı kurallarına uyulmuş olup; toplanan veriler üzerinde herhangi bir tahrifat yapılmamış ve bu çalışma 5.Uluslararası Spor Bilimleri Turizm ve Rekreasyon Öğrenci Kongresinde (7-9) Mayıs 2018 sözel bildiri olarak sunulmuştur. Alıntılama yapılan araştırmalara atıf yapılarak etik kurallara riayet edilmiştir.

Çıkar Çatışması: Yazarlar arasında herhangi bir çıkar çatışması yoktur.

Araştırmacıların Katkı Oranı Beyanı: 1. Yazarın \%70, diğer yazarların \%10’ar katkısı bulunmaktadir.

\section{KAYNAKLAR}

Akbay, S. ve Gizir, C. (2010). Cinsiyete göre üniversite öğrencilerinde akademik erteleme davranış1: akademik güdülenme, akademik özyeterlik ve akademik yükleme stillerinin rolü. Mersin Üniversitesi Ĕgitim Fakültesi Dergisi, 6(1), 60-78.

Albayrak, E. (2014). Üniversite ögrencilerinde beş faktör kişilik, akademik öz-yeterlik, akademik kontrol odă̆ ve akademik erteleme. (Yayınlanmamış Yüksek Lisans Tezi). Karadeniz Teknik Üniversitesi Eğitim Bilimleri Enstitüsü, Trabzon. 
Kaya-Saylam, D., Çamlıyer, H., Çamlıyer, H. ve Ekim, N. (2021). Spor bilimleri fakültesi öğrencilerinin akademik erteleme düzeylerinin incelenmesi. Ulusal Spor Bilimleri Dergisi, 5(2), 146-153.

Altunışık, R., Coşkun, R., Bayraktaroğlu, S. ve Yıldırım, E. (2017). Sosyal bilimlerde araştirma yöntemleri SPSS uygulamali (9, Bask1). Sakarya: Sakarya Kitabevi,

Balkıs, M. (2006). Öğretmen adaylarının davranışlarındaki erteleme eğiliminin, düşünme ve karar verme tarzları ile ilişkisi. (Yayınlanmamış Doktora Tezi). Dokuz Eylül Üniversitesi Eğitim Bilimleri Enstitüsü, İzmir.

Bojuwoye, O. (2019). Causes of academic procrastination among high school pupils with learning disabilities in 1lorin. International Journal of Technology and Inclusive Education (IJTIE), 8(1), 1404-1409.

Bulut, R. ve Ocak, G. (2017). Öğretmen adaylarının akademik erteleme davranışlarını etkileyen etmenler. $E$ Uluslararası Eğitim Araştırmaları Dergisi, 8(2), 75-90.

Çakıcı, D.Ç. (2003). Lise ve üniversite öğrencilerinde genel erteleme ve akademik erteleme davranışının incelenmesi. (Yayınlanmamış Yüksek Lisans Tezi). Ankara Üniversitesi Eğitim Bilimleri Enstitüsü, Ankara.

Çeri, B. K. Çavuşoğlu, C. ve Gürol, M. (2015). Üniversite öğrencilerinin akademik erteleme düzeylerinin Incelenmesi. International Journal of Social Sciences, 34(2), 385-394.

Çetin, N. (2016). Lise ögrrencilerinin akademik erteleme davranışlarının incelenmesi. (Yayınlanmamış Yüksek Lisans Tezi). Anadolu Üniversitesi Eğitim BilimleriEnstitüsü, Eskişehir.

Guzey, M. (2007). Akademik erteleme: Bir öğrenci klasiği. Türk Psikoloji Bülteni, 13(41), 84-86.

Gürültü, E. ve Deniz, L. (2017). Lise öğrencilerinin akademik erteleme davranışları ve sosyal medya kullanımları arasındaki ilişkilerin incelenmesi. Journal of Human Sciences, 14(1), 772-788.

Ekinci, E. (2011). Ortaöğretim öğrencilerinin akademik özyeterlik düzeyleri ve akademik erteleme davranışlarının öğrenilmiş çaresizlik düzeylerini yordama gücü. (Yayınlanmamış Yüksek Lisans Tezi). Gaziosmanpaşa Üniversitesi Sosyal Bilimler Enstitüsü, Tokat.

Eksi, H. ve Dilmac, B. (2010). Üniversite ogrencilerinin genel erteleme, karar vermeyi erteleme ve akademik erteleme duzeylerinin surekli kaygi acisindan incelenmesi. Uludag Universitesi Egitim Fakultesi Dergisi, $23(2), 433-450$.

Filiz, B. ve Doğar, Y. (2021). Beden eğitimi öğretmeni adaylarinin akademik erteleme eğilimlerinin öz düzenleme becerileri ve öz yeterliklerine etkisi. Milli Ĕ̆itim Dergisi, 50(230), 857-872.

Joubert, C. P. (2015). The relationship between procrastination and academic achievement of high school learners in North West province, South Africa. (Master of Arts). Universty of South Africa.

Karasar, N. (2012). Bilimsel araştırma yöntemi (24. bask1). Ankara: Nobel Yayıncılık.

Karataş, H. ve Bademcioğlu, M. (2015). Öğretmen adaylarinin akademik erteleme davranişlarinin beș faktör kişilik özellikleri ile açiklanmasi. Educational Research Association The International Journal of Research in Teacher Education, 6(2), 11-25.

Kim, K. R. \& Seo, E. H. (2015). The relationship between procrastination and academic performance: A meta Analysis. Personality and Individual Differences, 82, 26-33.

Kutlu-Abu, N. \& Saral, D. G. (2016). The reasons of academic procrastination tendencies of education faculty students, Online Journal of New Horizons in Education, 6(1), 165-169.

Kutlu, M. ve Demir, Y. (2016). Ergenlerdeki akademik erteleme davranışının incelenmesi. K. Ersanlı (Ed.). Hedefe Doğru Insan Psikolojik Danışma ve Rehberlik II Sempozyumu içinde (ss,378- 385), Samsun.

Lay, C. H. (1986). At last, my research article on procrastination. Journal of research in personality, 20(4), 474495.

Nayak, S. G. (2019). Impact of procrastination and time-management on academic stress among undergraduate nursing students: a cross sectional study. International Journal of Caring Sciences, 12(3),1480-1487. 
Onağ, O. A. Onag, Z. ve Yıldız, Y. (2012). Örgütsel vatandaşlik davranişi ile akademik erteleme eğilimi arasindaki ilişki: üniversite öğrencilerine yönelik bir araştirma (Manisa örneği). IIB International Refereed Academic Social Sciences Journal, 2(3), 30-43.

Özer, A. ve Altun, E. (2011). Üniversite öğrencilerinin akademik erteleme nedenleri. Mehmet Akif Ersoy Üniversitesi Ĕ̈itim Fakültesi Dergisi, 1(21), 45-72.

Özer, B. U., Demir, A. \& Ferrari, J. R. (2009). Exploring academic procrastination among Turkish students: Possible gender differences in prevalence and reasons. The Journal of Social Psychology, 149(2), 241257 ,

Rosario, M., Schrimshaw, E. W., Hunter, J. \& Levy-Warren, A. (2009). The coming-out process of young lesbian and bisexual women: Are there butch/femme differences in sexual identity development?. Archives of Sexual Behavior, 38(1), 34-49.

Sarıkabak, M., Eyuboğlu, E. ve Ayrancı, M. (2018. Investigation of the effect of emotional intelligence levels of bocce (petanque) athletes on academic procrastination behaviors. International Journal of Cultural and Social Studies (IntJCSS), 4(1), 163-177.

Senécal, C. Julien, E. ve Guay, F. (2003). Role conflict and academic procrastination: A self-determination perspective. European Journal of Social Psychology, 33(1),135-145.

Solomon, L. J. \& Rothblum, E. D. (1984). Academic procrastination: Frequency and cognitive-behavioral correlates. Journal of Counseling Psychology, 31(4), 503-509. DOI:10.1037/0022-0167.31.4.503

Şirin, E. F. ve Duman, S. (2018). Cinsiyete göre beden eğitimi ve spor yüksekokulu öğrencilerinde akademik erteleme davranışı: Genel erteleme ve akademik özyeterliğin rolü. Türk Spor Bilimleri Dergisi, 1(1), $1-10$.

Tice, D. M. \& Baumeister, R. F. (1997). Longitudinal study of procrastination, performance, stress, and health: The costs and benefits of dawdling. Psychological Science, 8(6), 454-458.

Toker, B. (2014). Bilişsel davranişçi kurama dayali olarak geliştirilen akademik erteleme davranışlyla baş etme beceri eğitimi psikoeğitim grup yaşantısının üniversite öğrencilerinin akademik erteleme davranışlarına etkisi. (Yayınlanmamış Yüksek Lisans Tezi). Muğla Sıtkı Koçman Üniversitesi, Eğitim Bilimileri Enstitüsü, Muğla.

Uzun-Özer, B. (2005). Academic procrastination: Prevalance, self-reported reasons, gender difference and it's relation with academic. (Yayınlanmamış Yüksek Lisans Tezi). Ortadoğu Teknik Üniversitesi Sosyal Bilimler Enstitüsü, Ankara.

Uzun-Özer, B. (2009). Bir grup lise öğrencisinde akademik erteleme davranışı: Sıklığı, olası nedenleri ve umudun rolü. Türk Psikolojik Danışma ve Rehberlik Dergisi, 4(32), 12-19.

Vural, L. ve Gündüz, G. F. (2019). Öğretmen adaylarının akademik erteleme davranışları ile bilişsel farkındalık düzeyleri arasındaki ilişki. Elementary Education Online, 18(1),307-330.

Yaycı, L. ve Düşmez, İ. (2016). Adolesanların akademik erteleme davranışlarının bazı değişkenler açısından incelenmesi. OPUS Uluslararası Toplum Araştırmaları Dergisi, 6(10), 80-101.

Yiğit, R. ve Dilmaç, B. (2015). Ortaöğretimde öğrencilerinin sahip oldukları insani değerler ile akademik erteleme davranışlarının bazı değişkenler açısından incelenmesi. Dumlupınar Üniversitesi Sosyal Bilimler Dergisi, 3, 159-177.

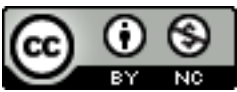

Bu eser Creative Commons Atıf-Gayri Ticari 4.0 Uluslararası Lisansı ile lisanslanmıştır. 